\title{
The linguistic sign: Metonymy and virtuality*
}

\author{
Adam Glaz (Lublin)
}

\begin{abstract}
Grounded in a rich philosophical and semiotic tradition, the most influential models of the linguistic sign have been Saussure's intimate connection between the signifier and the signified and Ogden and Richards' semiotic triangle. Within the triangle, claim the cognitive linguists Radden and Kövecses, the sign functions in a metonymic fashion. The triangular semiotic model is expanded here to a trapezium and calibrated with, on the one hand, Peirce's conception of virtuality, and on the other hand, with some of the tenets of Langacker's Cognitive Grammar. In conclusion, the question "How does the linguistic sign mean?" is answered thus: it means by virtue of the linguistic form activating (virtually) the entire trapezium-like configuration of forms, concepts, experienced projections, and relationships between all of the above. Activation of the real world remains dubious or indirect. The process is both metonymic and virtual, in the sense specified.
\end{abstract}

\section{$1 \quad$ Laying out the trail}

The question "What is language?" is comparable with - and, some would say, hardly less profound than "What is life?", the presuppositions of which circumscribe and unify the biological sciences.

John Lyons (1981: 1)

Lyons continues the thought in the epigraph above by pointing out that the question of the nature of life may not be what "the biologist has constantly before his mind in everyday work" (1) - but ultimately such is the quest in all research on living organisms. The same pertains to language: because of its intimidating complexity, informed linguistic analyses must be "local", and yet their import is "global" in linguists' joint effort to discover what language is and what it is like. It is with a view to achieve this end that the present study is concerned with the nature of the linguistic sign. For if language is about meaning, then this dictates the nature of language as a whole:

Our understanding of the nature and role of [...] language essentially depends on appreciating the role of the sign... Both getting to know something and communicating these contents to another are grounded in the sign - we therefore say that human acquisition of knowledge and human speech involve selectively framed meaning, that is, the content represented in the sign.

\footnotetext{
* I wish to thank Bill Sullivan and Hubert Kowalewski for their comments and readiness to discuss ideas with me. Thanks are also due to anonymous reviewers of an earlier draft of this paper. Naturally, the responsibility for the views expressed and for the errors committed here rests with me alone.
} 
(Krąpiec 1995: 21-22; transl. A.G.)

But the task of "appreciating the role of the sign" is daunting, to say the least. Ferdinand de Saussure (2006: 3) describes it in this somewhat surrealist passage as "absurd":

A linguistic entity is quite unique in that it involves the association of two distinct elements. If we were invited first to determine the chemical classification of a sheet of iron, gold, or copper, and then the zoological species of a horse, cow, or sheep, these would be two easy tasks. But if we were asked to determine what "species" is represented by the odd combination of an iron plaque attached to a horse, a gold plate on a cow, or a sheep adorned with something copper, we would exclaim that the task was absurd. The linguist has to realize that it is precisely this absurd task that faces him right from the very outset.

(Saussure 2006: 3)

Scholars proceed, continues Saussure (2006: 4), by doing the manageable, i. e. by isolating ideas from forms and focusing on each kind of entity in turn. But for this to count as linguistics, the analyst must ultimately come to grips with "the point of connection between these domains".

I will therefore begin by presenting selected conceptions of the linguistic sign in the history of ideas, which will constitute the necessary backdrop for a discussion of the sign's metonymic nature. My key proposal will next be advanced: the linguistic sign is metonymic because it is virtual. I believe these considerations will bring us nearer to a more satisfactory understanding of language.

\section{The linguistic sign: a dyad, a triad or more?}

When Krąpiec (see above) writes of content being represented in the sign, he is clearly subscribing to the medieval formula aliquid stat pro aliquo 'something stands for something else'. In fact, the legacy of the formula can be found in all dyadic models of the linguistic sign, including the most famous Saussure's "two-sided psychological entity" (Saussure 1916/1966: 66), composed of a concept as the signified (signifié) and a sound-image as the signifier (signifiant). The relationship between the two is claimed to be "intimate" (one side "recalls the other" [66], as in a sheet of paper [113]) and arbitrary. But the linguist's recognition of the role of motivation significantly weakens the arbitrariness view with which he is usually credited (see below). ${ }^{1}$

Saussure's idea of an intimate connection between the sign's two sides found a continuation, some seventy years later, in Ronald Langacker's (1987) notion of the linguistic unit as a bipolar construction: ${ }^{2}$ the semantic pole as a sub-area of semantic space and the phonological pole as a sub-area of phonological space. In general terms, the views of the two linguists are not so disparate as is usually assumed. For both, meaning is a conceptual entity (Saussure: the signifié is conceptual; Langacker: meaning reduces to conceptualization). For both, the formal side of the sign is also conceptual (Saussure: the sound is effectively a sound-image;

\footnotetext{
${ }^{1}$ Some of the major representatives of the non-arbitrary stance include Benveniste (1939), Bolinger (1949), or Jakobson (1962); support for the conventional view can be found in e. g. Whitney (1875). Broad-spectrum surveys of the issue of motivation are Cuyckens et al. (2003), Radden and Panther (2004), or Panther and Radden (2011). For a discussion of motivation in the context of "naturalness", see Kowalewski (2016).

${ }^{2}$ Langacker's explicit reference to Saussure at the beginning of his (1987) magnum opus is singular - in both senses of the word.
} 
Langacker: phonological space is contained in semantic space, which is in turn contained in conceptual space). Apparently, the one major difference between Saussure and Langacker is that for the latter, the two poles make up a symbolic, rather than an arbitrary unit (Figure 1).

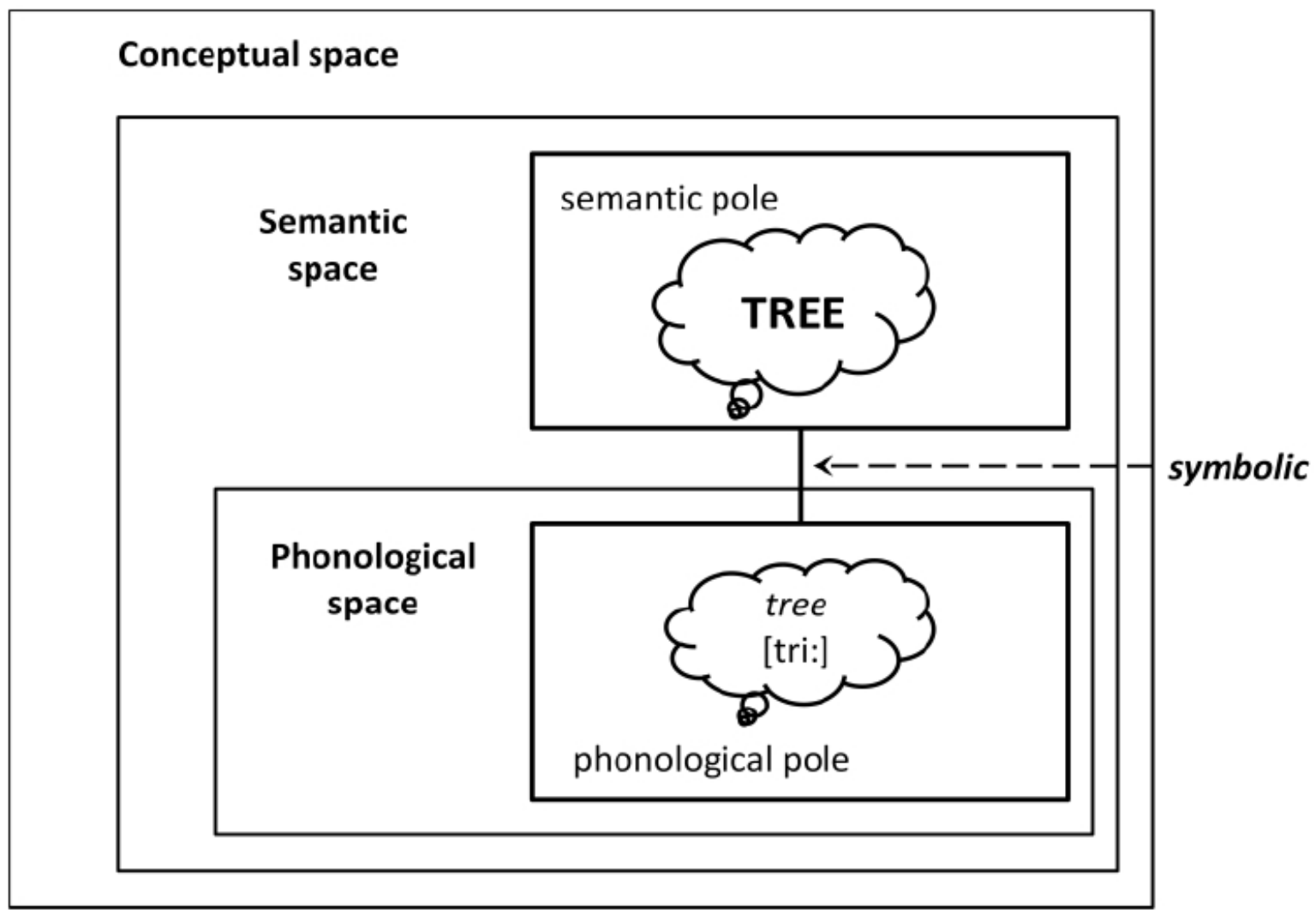

Figure 1: Langacker's model of a symbolic unit

However, Saussure (1916/1966 133) weakens his arbitrariness view more than is usually acknowledged: "the whole system of language is based on the irrational principle of the arbitrariness of the sign, which would lead to the worst sort of complication if applied without restriction". The restrictions Saussure (1916/1966: 133) identifies are associative and syntagmatic, e.g. "dix-neuf is supported associatively by dix-huit, soixante-dix, etc. and syntagmatically by its elements dix and neuf', linked through interdependence and mutual conditioning. These associations function as motivation of linguistic signs.

How does this relate to Langacker's symbolic alternative? Alas, Langacker never delves into a serious discussion of the nature of symbolicity but it seems that it may derive as much from Saussure's as from Charles S. Peirce's semiotic model. For Saussure (1916/1966: 68), a symbol "show[s] at least a vestige of natural connexion between the signal and its signification", whereas for Peirce (1894/1998: 9), a symbol is "a conventional sign, or one depending upon habit (acquired or inborn)". As if in a continuation of these two lines of thinking, Langacker's symbolic is taken to be both motivated and conventionalized (cognitively entrenched through usage). Indeed, it may be motivated because it is conventionalized (linguistic habit is a motivation) or possibly the reverse: it becomes conventionalized (habitually used) because it is motivated, if only through historical 
inheritance. In short, a claim can be made for a bidirectional, mutually-conditioning relationship between the two notions. ${ }^{3}$

But a felicitous countering of the notion of arbitrariness came much earlier in the work of Dwight Bolinger, whose reasoning first proceeds along moderate lines:

It has never been contended that complex utterances are arbitrary in the same sense in which arbitrary has been applied to morphemes. When I say The fire consumed the house I "might as well" say $m a b u$, an arbitrary sign to symbolize the entire occurrence. The fact is, however, that in my language experience parts of the utterance correspond to parts of the event - and the whole utterance is to that extent not arbitrary, for it is articulated in some such way (remote as you please to call it) as the event itself. Here meaning and form affect each other.

(Bolinger 1949: 55)

Then, however, the argumentation becomes more radical:

Now there is no reason why this habit of non-arbitrariness, of point-to-point correspondence, should stop at the level of complex utterances. It continues to the level of morphemes and beyond. And herein, at the floor of language where phonologists and morphemicists have made their stand and where signs have been pictured as unimpeachably arbitrary, we are challenged to find proof that language is still systemic.

(Bolinger 1949: 55)

The author upholds the idea of the systemic nature of language by providing several examples of how "a large part of the time similar forms will tend in the direction of similar meanings" (Bolinger 1949: 62). One must of course be wary of jumping to hap-hazard conclusions; nonetheless, Bolinger's examples of sound-symbolic effects cannot be easily dismissed: units do tend to cluster if they resemble one another in both form and meaning, "thereby drawing closer together and pulling other forms into their orbit" (Bolinger 1949: 59). Such may have been the case, for example, in the change of Old English laewed 'non-clerical, lay' to Modern English lewd 'lustful, lascivious' by analogy to other words with the vowel [u:] with unpleasant connotations (lurid, lugubrious, allure, putrid, shrew, etc.), resulting in meaning pejoration (Kardela 1990: 32). ${ }^{4}$

However, a form-content similarity functions not only as motivation within the sign but is motivated itself. In the words of Karl Bühler:

Man, who has learned to read and to interpret the world by uttering sounds, feels that the medial implement of language with its autonomy pushes him aside from the fullness of what the eye can drink, the ear can hear, the hand can "grasp", and he looks for the way back, tries to attain as full a grasp of the concrete world as possible while continuing to utter sounds. That is the simple account of the motivation for the phenomenon of sound symbolism [...].

(Bühler 1934/2011: 220)

The speaker is "pushed aside" from the concrete world, Bühler (1934/2011: 35) continues, because language generally blocks sound symbolism: it is only allowed in what he calls small, individual sound-symbolic "pockets". The author further recognizes that the sign does not only symbolize objects and events, but also acts as a symptom of the speaker's inner states

\footnotetext{
${ }^{3}$ In Kowalewski (2016), the arbitrary vs. motivated opposition loses much or all of its power. The author argues for a redefinition of naturalness, such that in effect everything in language is motivated and the whole of language acquires the status of a symbolic rendering of human conceptualizations.

${ }^{4}$ For a series of studies on sound symbolism cf. Hinton et al. (1994).
} 
and a signal of its appeal to the hearer. The sign's symbolic field thus embraces the speech participants and their hic et nunc. It is within the symbolic field thus understood that words realize their symbolic potential - just as a cross on a map or a note in a music score function as symbols within their respective fields.

Symbolization also plays a vital role in Ogden and Richards' (1923/1952) triadic model. A triad of this kind arises when the aliquo (recall: aliquid stat pro aliquo) is divided into sense and reference, such as Frege's (1892) Sinn and Bedeutung or all kinds of parallel constructs. And even if Ogden and Richards' idea of the triangle (Figure 2) had been predated in the work of the Stoics (early $3^{\text {rd }}$ c. BC onwards), Boethius $\left(5^{\text {th }}-6^{\text {th }}\right.$ c.) or, in modern times, of Heinrich Gomperz (1908) or Charles Peirce, it is their conception that has gained the widest currency.

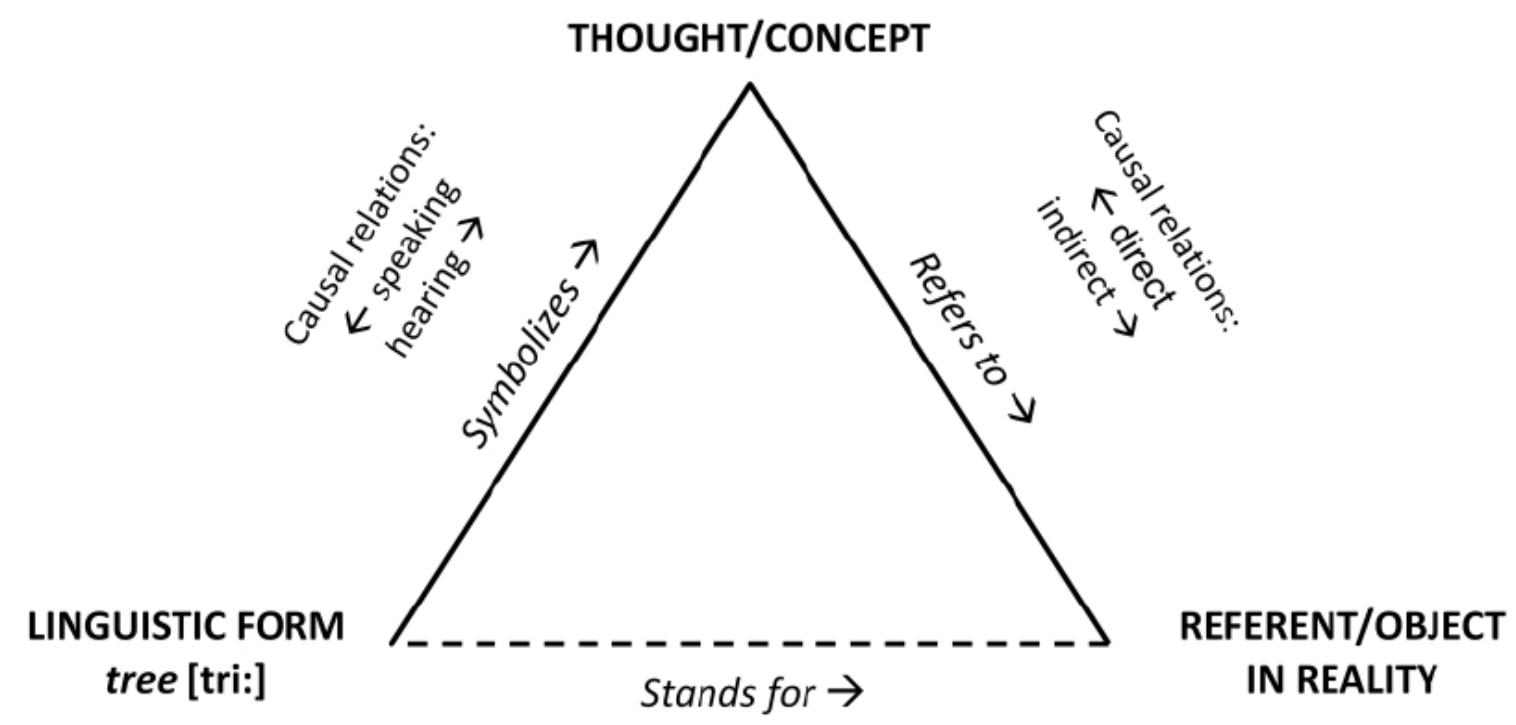

Figure 2: Ogden and Richards' (1923/1952: 11) semiotic triangle (labels modified: original symbol-here linguistic form; original thought or reference - here thought/concept; original referent - here referent/object in reality)

The triangle's three apices are linked through several kinds of relationship. First, the linguistic form symbolizes the concept. In speaking, the form is partly dictated by the idea we have in the mind, and partly by social and psychological factors (e. g. the desire to imitate through linguistic form a certain feature we identify in or ascribe to the concept we construct). When hearing, the forms cause us to construct (or: we infer on their basis) certain ideas, so as to assume an attitude that "more or less" corresponds to that of the speaker. Along the triangle's right side, in turn, the concept refers to the object in reality. The relationship along the bottom side of the triangle, i. e. between the form and the referent, can only be indirect: the form stands for the referent but the conceptualizer can only access the latter via the concept, as when we talk of Napoleon and can only do so through "a very long chain of sign-situations intervening between the act and its referent: word - historian - contemporary record - eyewitness - referent" (Ogden/Richards 1923/1952: 11).

Admittedly, a degree of closure along the triangle's bottom side has been suggested on at least three counts: (i) onomatopoeia and sound symbolism; (ii) Malinowski's (1923/1952) conception of the active use of language to handle objects ("word magic" in Ogden and 
Richards' terminology), and (iii) the cognitivist idea of experiential realism and embodiment of cognition (Lakoff 1987; Lakoff/Johnson 1999). None of the three arguments, however, is convincing. The limited role of sound symbolism has already been mentioned. Word magic rests on the idea that people believe that words can handle objects - and this is only possible in and through culture, or community-grounded symbolization, and so we are back to Bühler's symbolic field (the cultural aspect is addressed in more detail below). As far as experiential realism is concerned, it is a matter of emphasizing either experience or reality. While an emphasis on the latter will bring us closer to the triangle's bottom right apex, the cognitivist approach is more likely to put the onus on experience. This is not to deny either the very existence or the importance of reality, but to suggest that experiential access to it leaves little room for us to know what reality is "really like". Experiential realism highlights the triangle's right side, while linguistic expression of experience moves us further down to the bottom left apex. In this way, all three apices of the figure are involved - but via its left and right sides!

Bearing all this in mind, and without ignoring the differences between the views of the individual scholars, Saussure, Ogden and Richards, and Langacker all subscribe to the idea that the meaning of the sign is mind-dependent and grounded in the conceptualizing subject (a view known as semiotic conceptualism). In what follows, I will be trying to find support for this view in the phenomena of metonymy and virtuality. However, before we embark on the task, it is necessary to consider certain modifications to Ogden and Richards' triangle.

\section{The semiotic trapezium and the linguistic worldview conception}

Mine is by no means the first attempt to do so: because Ogden and Richards' tripartite account was thought either insufficient or inaccurate, modifications were proposed by e. g. Stephen Ullmann (1962), Kurt Baldinger (1967) or Klaus Heger (1969). The latter's idea of a trapezium, with as many as six "stops" along its apices and sides, has served as a very general inspiration for the proposal presented here, although my model is grounded in a different tradition and results from a different line of reasoning.

That tradition is the linguistic worldview conception, discussed at length, implemented in analyses, and critically evaluated in Głaz et al. (2013). A convenient definition of the notion can be found in Jerzy Bartmiński's (2012) cognitive ethnolinguistic approach, where the linguistic worldview is understood as

$[\ldots]$ a language-entrenched interpretation of reality [...] expressed in the form of judgements about the world, people, things, events. It is an interpretation, not a reflection; it is a portrait without claims to fidelity, not a photograph of the real object. The interpretation is a result of subjective perception and conceptualization of reality performed by the speakers of a given language; thus, it is clearly subjective and anthropocentric but also intersubjective (social). It unites people in a given social environment, creates a community of thoughts, feelings and values. It influences ... the perception and understanding of the social situation by a member of the community.

(Bartmiński 2012: 23) 
The definition can be rather neatly incorporated into the semiotic triangle (Figure 3$)^{5}$

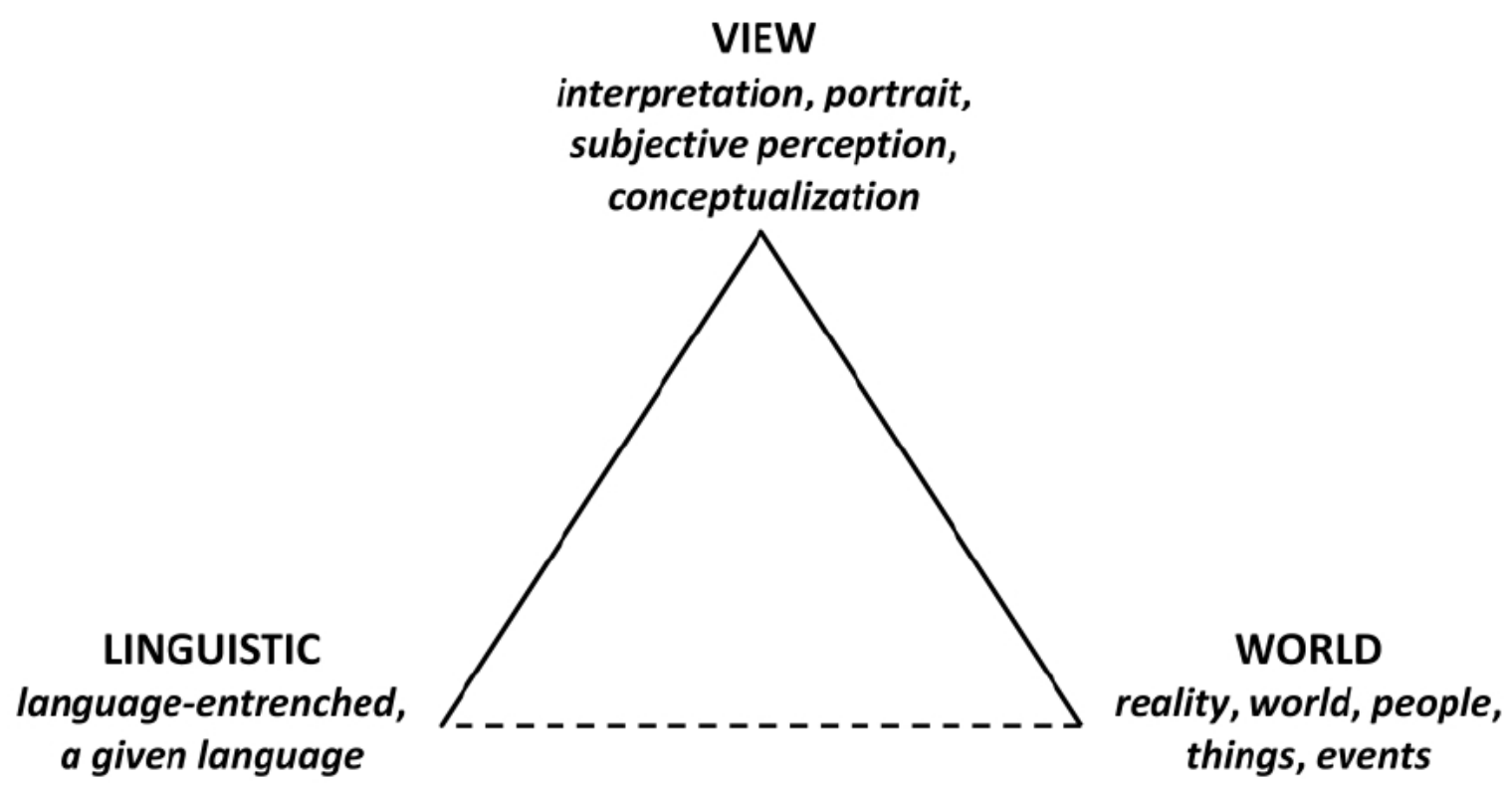

Figure 3: Bartmiński's linguistic worldview conception aligned with the semiotic triangle

Crucially, however, note that besides the three apices, Bartmiński's definition makes reference to a novel, emergent quality: the social dimension, culture-based intersubjectivity, a community of thoughts, feelings, and values. With regard to this broad understanding of culture I would like to make two claims, hardly original but systematized and vital for the present argumentation.

The first claim, perhaps obvious but worthy of mentioning in this context, is that the world is not accessible to us as such, but only as conceptualization and through culture. Consider what seems to be a mundane experience of water. For most of us, water is accessible in the form of rivers, lakes, waterfalls, rain, the sea, showers, taps, garden hoses, etc. Counterintuitive as it may seem, the objective existence of water is these forms - even if undeniable - is in fact secondary, because the same can be said about water in the Earth's mantle. Yet, the latter form of existence is probably meaningless for most people on the planet (as is, for that matter, the very notion of the Earth's mantle), especially for members of relatively self-contained and close-knit communities that have not developed elaborate technology but rather organize their lives according to natural cycles (seasons, tides, etc.). Therefore, there is no water "as such" but only water in its cultural projection: for members of Polish folk communities it has a rich and elaborate symbolism of rebirth, life, purification, danger, and destruction. Geologists studying the Earths' mantle or chemists describing water as $\mathrm{H}_{2} \mathrm{O}$ also operate within their respective "cultures": they are conditioned by the goals of their research, the available

\footnotetext{
5 A controversy might arise to the effect that the "linguistic" and the "view" side of the model are not separable, while the diagram suggests something else (cf. de Saussure's metaphor of the linguistic sign as a sheet of paper, but also Humboldt's view of language as a medium of thought ('bildendes Organ des Gedankens'). However, the idea here is to align Bartmiński's model with that of Ogden and Richards, which can be done at some expense of precision. Thus, no major claims are made here as to the relationhsips between the triangle's elements, the purpose of the diagram being merely illustrative. Also, the linguistic worldview conception rests (among others) on the idea that there are "worldviews" and "linguistic worldviews", which need not correlate, or at least not perfectly. Having said this, in what follows I do make a claim not only as to the inseparability of "language" and "view" but also as to the holistic nature of the entire configuation.
} 
technology, the desired level of information detail, the importance of this information for specific purposes, etc. The three cultures (now without the quotation marks), as well as many others, are sufficiently different from one another to be said to contain projected images of water. The projections results from and are motivated by people's salient experiences - this is what I understand, in a broad sense, as culture. Therefore, instead of the linguistic worldview, it is probably more appropriate to speak about the linguistic view of a cultural-world.

A compatible but more cognitively-oriented approach is Ray Jackendoff's (1983) distinction between the real world, the projected world (also called the experienced/phenomenal world) and conceptual structure. For example, the actually occurring real-world radiation leads to the emergence of a theoretical construct linked to it. But scientific investigation can focus on the projected constructs and their relationship to humans, largely ignoring the reallife phenomenon in its "objective" shape: radiation of a certain kind can be experienced as light of various colours (thus producing the concepts COLOUR, RED, BLUE, and others), as heat, etc. Other kinds, such as X-rays, are not experienced directly (though they can be detected and measured, and the long-term results of their operation are experienced), so that the concept X-RAY "has no projected counterpart" (Jackendoff 1983: 32). Importantly, projections and resultant concepts are dictated and interpreted by and through culture in the broad sense specified above.

A reconciliation of Bartmiński's and Jackendoff's accounts is presented in Figure 4, where the right side of the triangle is split to produce a semiotic trapezium.

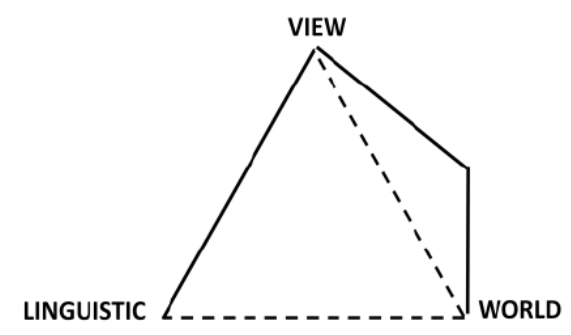

(a)

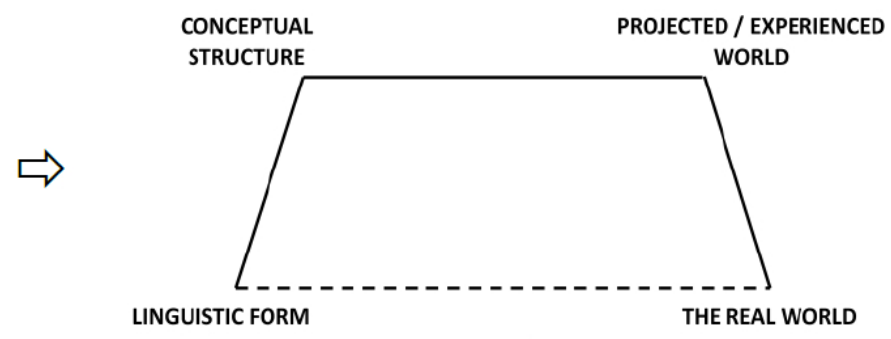

(b)

Figure 4: (a) the division of the right side of Ogden and Richards' semiotic triangle; (b) the resultant trapezium

The second claim I would like to advance concerns the trapezium's left side: conceptual structure is also entrenched in linguistic forms (recall Bartmiński's idea of the linguistic worldview as "a language-entrenched interpretation of reality"): these are not only physical, acoustic events or Saussure's sound images but contextualized texts and acts of discourse. Language is thus both a product and a carrier of culture, its symbolic expression. ${ }^{6}$ Culture thus enters the stage in two regions of the trapezium and extends throughout its top and left sides, so that another change of basic terminology is called for: instead of the linguistic view of a cultural-world we are dealing with a more elaborate linguistic-cultural view of a projected-and-cultural world. Three out of the four of the trapezium's apices are thus incorporated into culture's sphere of influence, while the bottom right apex, representing

\footnotetext{
${ }^{6}$ Bartmiński expresses the perennial problem of the culture-language interface as "a paradox of reciprocal dependence" (2001: 17).
} 
reality, is accessed only indirectly: it may be the primary source of experience, but it is filtered through cognition, culture, and conventionalized linguistic expression (Figure 5).

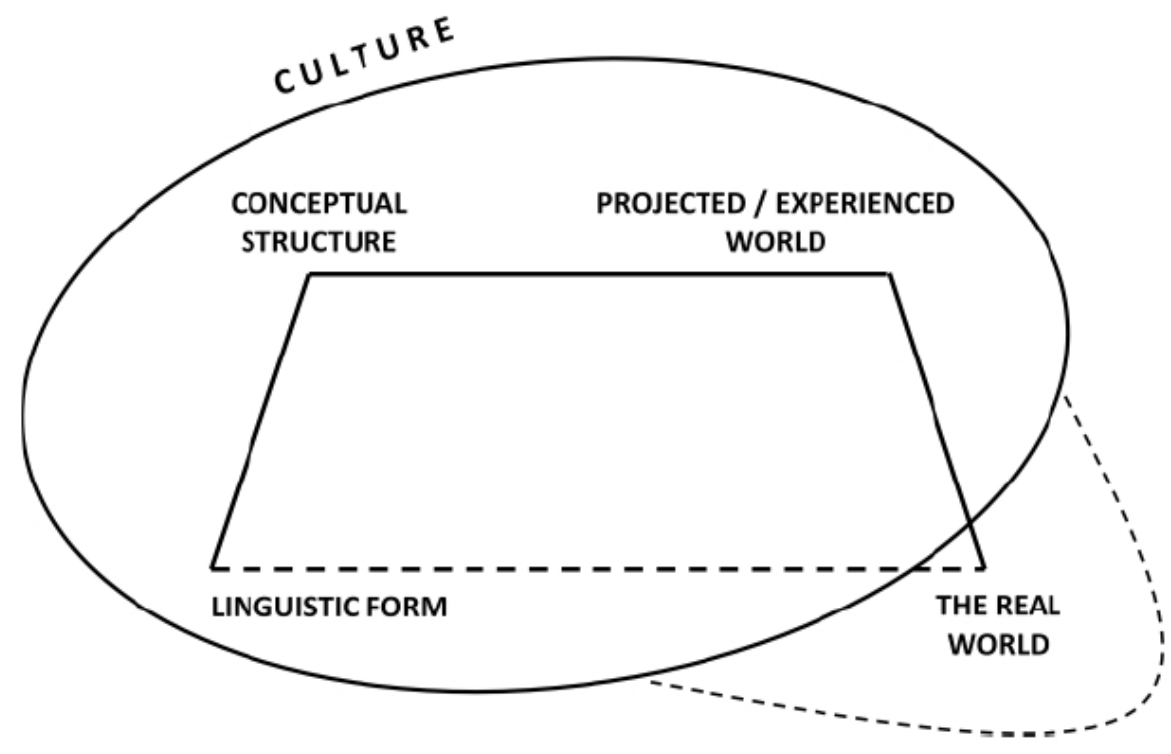

Figure 5: The semiotic trapezium with the cultural component (the ellipse)

Against this background, we can now propose to consider, in turn, two crucial properties of the linguistic sign: metonymy (Section 4) and virtuality (Sections 5-6).

\section{$4 \quad$ Metonymy in the sign}

Although Ogden and Richards (1923/1952: 9) never use the term, one of their examples is a clear manifestation of metonymy: by saying that a gardener mows the lawn, when it is the mower that does the cutting, the speaker employs what in contemporary cognitive linguistics could be called a DOER FOR THE INSTRUMENT metonymy. ${ }^{7}$ Therefore, regardless of whether we are dealing with a dyadic configuration (Saussure, Langacker, Bühler), a triadic configuration (Ogden and Richards, Peirce), or a tetradic one (the trapezium), metonymy can be found in the very nature of the linguistic sign, an idea expounded in Radden and Kövecses (1999). Metonymy is a cognitive operation, whereby A interrelates A and B (i. e., A does not stand for $\mathrm{B}$ alone, as in metaphor, but for $\mathrm{A}+\mathrm{B}$ ). $\mathrm{A}$ and $\mathrm{B}$ are linked through contiguity (usually partitive, spatial, temporal, or causal), which produces a novel, complex meaning. Radden and Kövecses quote Beatrice Warren's (1999: 128) simple but brilliant examples: "We do not refer to music in I like Mozart, but to music composed by Mozart; we do not refer to water in The bathtub is running over, but to water in the bathtub".

The authors identify several metonymies within the semiotic triangle, the most fundamental of which is what they call sign metonymy: this is when the form stands for the form-concept

\footnotetext{
7 The more meticulous reader will point out that in fact it is the blade of the mower that performs the action. What really matters, however, is the nature of the metonymic process.
} 
alignment, i. e. for the whole sign. ${ }^{8}$ Figure 6 illustrates this and three kinds of reference metonymies, also identifiable within the triangle.

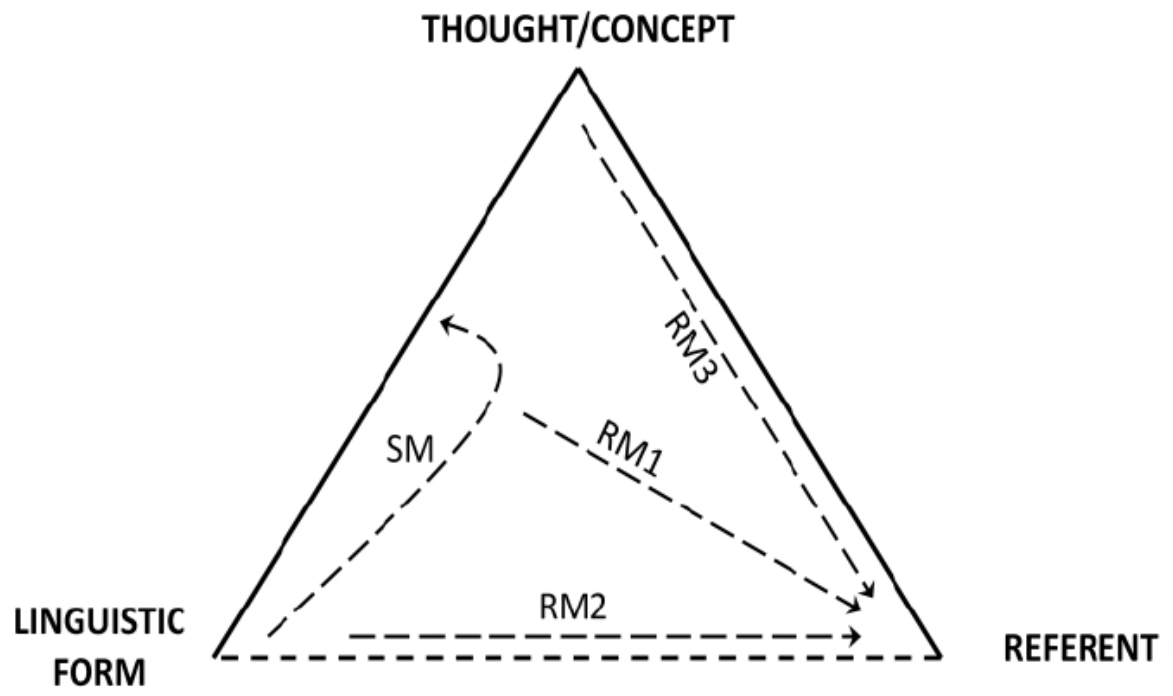

Figure 6: Metonymies within the semiotic triangle (based on Radden and Kövecses 1999: 23). SM: sign metonymy (form for sign). RM1: reference metonymy "sign for referent". RM2: reference metonymy "form for referent". RM3: reference metonymy "concept for referent"

Four more metonymies can be identified in the trapezium, three of which I will call projection metonymies and one being the fourth type of reference metonymy (Figure 7).

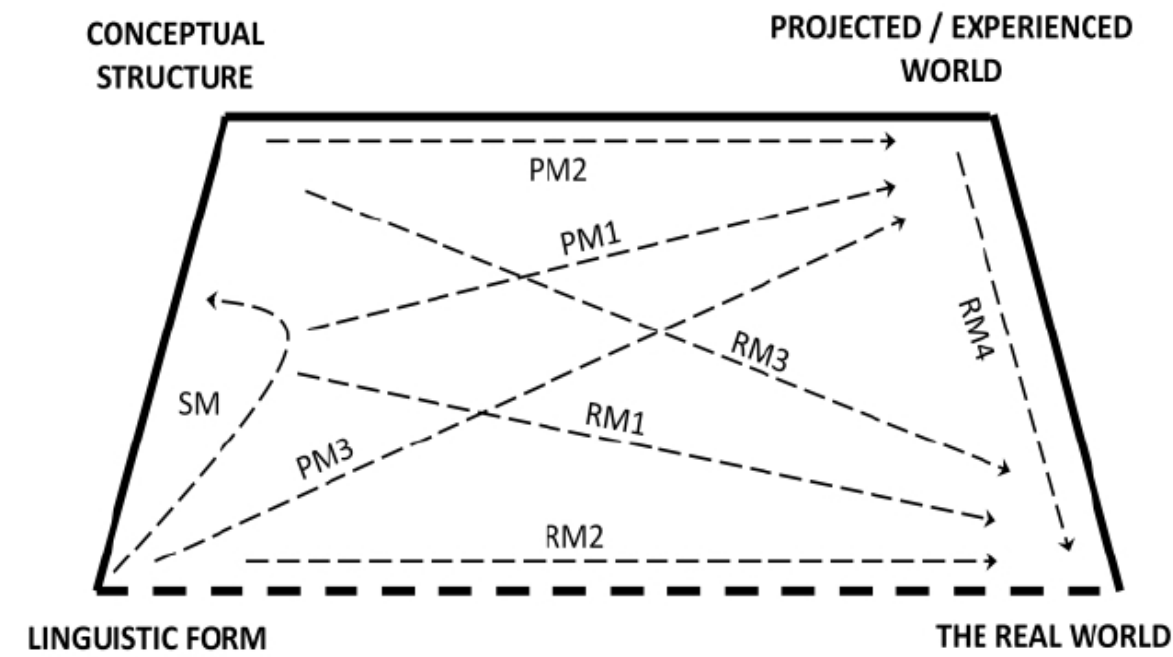

Figure 7: (More) metonymies within the semiotic trapezium. PM1: projection metonymy (sign for projected world); PM2: projection metonymy "concept for projected world"; PM3: projection metonymy

"form for projected world"; RM4: reference metonymy "projected world for referent"

\footnotetext{
${ }^{8}$ The reader must be forewarned of certain inadequacies in Radden and Kövecses's otherwise very methodical work. They make repeated claims to the effect that "the form metonymically stands for the concept it denotes" (Radden/Kövecses 1999: 24). This basically faulty formulation of metonymy (which is not "form for concept" but "form for sign", i. e. "form for form+concept") is used "for the sake of simplicity [...] with the proviso, however, that the metonymic process is not understood to be one of substitution" (Radden/Kövecses 1999: 19). In my opinion, the drive to avoid obscurity in this particular case produced the opposite effect.
} 
The crux of Radden and Kövecses's (1999: 24) argument is that sign metonymy is a defining property of language, a mechanism inherent in its very fabric: "Since we have no other means of expressing and communicating our concepts than by using forms, language as well as other communication systems are of necessity metonymic. It is also for that reason that we fail to notice the metonymic character of language" (Radden/Kövecses 1999: 24). My contribution to this idea, which I develop below, consists in two further modifications, the first of which derives from Langacker's notion of conceptualization. I propose that metonymy be viewed in a dynamic, rather than static sense: when $\mathrm{A}+\mathrm{B}$ is conceptually accessed through $\mathrm{A}$, the conceptualization is to be seen as a process, not a product. ${ }^{9}$ Therefore, A does not stand for $\mathrm{A}+\mathrm{B}$ (remove the stat from the medieval formula) but activates $\mathrm{A}+\mathrm{B}$. It is in this sense that I would like to see Radden and Kövecses's term interrelates. Secondly, the form will be claimed to activate not the dyadic form-concept alignment but (nearly) the whole trapezium (as in Peirce's dynamic semiosis) with all its internal tensions and relationships.

Why should this be so? Let me answer in this way: because it is hardly imaginable to be otherwise. How can the form water evoke the water/WATER (form/CONCEPT) configuration without at the same time evoking the projected world, given the complex and inextricable dependencies between them described above? How can, in a chain of relations, the projected world fail to correspond, if only indirectly, to the real world? Recall that the latter is claimed to never enter the stage in the objective sense, "as it is", hence we are talking about the activation of "nearly the whole trapezium". Various facets of the trapezial configuration may be more or less salient, depending on the context or speaker's intentions this includes the form itself, as in poetry or wordplay. In short, with some reservation as to the bottom right "reality" apex, activated is always the whole configuration, although probably not all its components to the same degree of salience.

To recapitulate this section: language is inherently metonymic because metonymy is part and parcel of the basic unit of language, the linguistic sign. We will now consider where metonymy comes from, i. e. whether it can be explained in terms of another, perhaps a more fundamental process.

\section{$5 \quad$ Metonymy through virtuality}

My take on the issue is that it indeed can: the linguistic sign is not only metonymic but it is also virtual. To be more precise, it is metonymic because it is virtual: the form activates the whole trapezium ${ }^{10}$ because it acts as a virtual trapezium.

Two major aspects of virtuality have usually been emphasized: its potentiality status and its relation to reality:

Over the past five centuries the word virtuality [...] has been used to denote a power, a potentiality, and an embodiment or essence as a certain kind of substituted greater-or-lesser reality. [...] Sir William Hamilton regarded a condition of virtuality as an unperfected reality.

\footnotetext{
9 For Langacker, a network of meaning relationships (and by extension any conceptualization) "is not something a speaker has, but rather what he does" (1987: 382).

10 To simplify matters, I say "the whole", but bear in mind the qualification introduced above as to the indirect link with reality, which may only be approached, rather than fully activated.
} 
Hegel characterized space as Ansichsein (Being-in-itself), as "only abstract subsistence or virtual being." And Heidegger characterized all of history as a kind of virtuality.

(Esposito 2002: 1)

In today's common understanding, virtual reality or virtual space is equated with cyberspace, "a space that exists only through interaction with computers" (Smith 2009: 95). As far removed as the two seem to be, this understanding has developed from the late Medieval notion of virtus, derived from the Latin vir 'man'. The Latin word related to the Ancient Roman notion of virtue that connoted masculinity, courage, valour, and power - cf. its later adoption into English as virtue. Virtus is activated when a certain notion is contained (virtually) in an object. It happens so, says a commentator to the work of John Duns Scotus, "if the object has the power or virtus of producing the notion in the mind" (Wolter in Scotus 1307/1975: 528). For example, a sphere is not strictly speaking circular but it is thought to contain the notion of a circle. Similarly, in digitally produced virtual reality, an architectural design programme may "contain" a house in that it evokes "the image of a house on the screen, or in the mind, but does not actually have the form of a house" (Crocker 2001: 58-59). Virtuality in this sense is thus a capacity to be, an inherent potential, and accordingly virtually in English means 'nearly'.

But in non-cyber contexts, virtuality may be viewed as something more than mere potentiality or, in fact, as very different from it. Gilles Deleuze (1966/1988, 1968/1994), for example, juxtaposes the virtual, not with the real (which is paired with the possible as its opposite), but with the actual: the virtual is not realized, being fully real already, but actualized. Actualizations of a virtual idea proceed through difference, divergence, and creation. Deleuze's example is that of hurricanes, which form when winds and ocean currents reach singular points. These points are virtual for each actual hurricane, where all hurricanes, sharing the same virtual structure, are (different) actualizations of that structure. In this sense, the virtual for Deleuze is a dynamic being "present only in instances of becoming" (Echard 2006: 8). Echard applies this conception to music: virtualities may take various shapes, as when a music score and a performance "actualize a virtual musical object" in distinct ways (8). Therefore, Deleuze's virtual is not the same as virtual reality in the sense of cyberspace; indeed, "[d]igital technologies have a remarkably weak connection to the virtual", because of the "enormous power of their systematization of the possible" (Massumi 2002: 137). Cyberspace in this approach is viewed as possible, rather than as virtual: systematization of the possible leaves little room for difference and creativity.

A continuation of these ideas can be found in Slavoj Žižek's conception of the reality of the virtual (most succinctly presented in Wright's 2004 documentary). His examples include paternal authority, which is truly effective only when it remains unactualized in the form of physical or other direct coercion. Similarly in physics: attractors (i. e. physical properties towards which a system evolves) are virtual forms that nevertheless really structure the actual particles (as when filings tend to assume a certain shape in a magnetic field). Relating to Einstein's curvature of space, Freud's trauma, or political and economic issues, the philosopher argues that the real does not have content but is "a structural gap, an entirely nonsubstantial category, [...] a pure difference [...] prior to what it is the difference between" (in Wright 2004). It is the virtual that sways the scepter of efficacious influence. 
Both Deleuze's and Žižek's conceptions of the virtual bear affinity - premeditated or not - to Charles Peirce's (1902: 763) succinct definition: “A virtual $X$ (where $X$ is a common noun) is something, not an $X$, which has the efficiency (virtus) of an $X$ '. Peirce's exemplification is that of animal instincts:

The instincts connected with the need of nutrition have furnished all animals with some virtual knowledge of space and of force, and made them applied physicists. The instincts connected with sexual reproduction have furnished all animals at all like ourselves with some virtual comprehension of the minds of other animals of their kind, so that they are applied psychists.

(Peirce 1899/1998: 51)

It is for this reason that virtual must not be confused with potential, which "is almost its contrary. For the potential $X$ is of the nature of $X$, but is without actual efficiency" (Peirce 1902: 763). Virtuality, in Peirce's example, is "a capacity to [actually, A.G.] act without reasoning as if reasoning had occurred" (Esposito 2002: 3). If $X$ is reason, and although instinct is not $X$, it is virtual $X$ : effectively, instinct is reason. This conception can now be calibrated with Langacker's apparently very different but ultimately compatible account.

\section{Virtuality in Cognitive Grammar}

Langacker's model differs from Peirce's in the sense that it involves virtuality as a linguistically grounded cognitive operation (Figure 8).

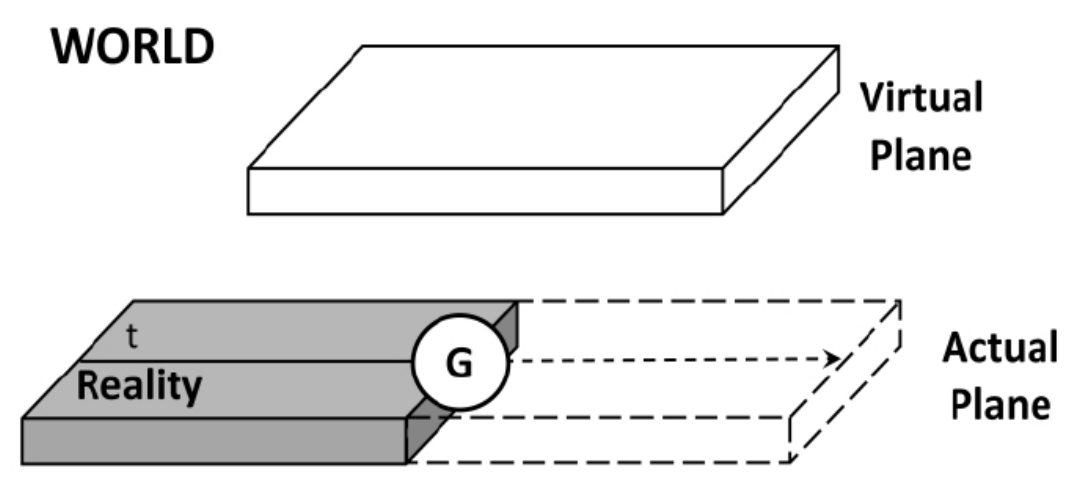

Figure 8: Langacker's model of virtuality (based on Langacker 1999: 43, Figure 1)

Within a given world there is actual plane and virtual plane. One aspect of actual plane is reality, i. e. a body of events, objects and occurrences that a given conceptualizer accepts as having happened or as having been realized. It evolves along time's arrow, with the ground (G, i. e. the speech event, its participants and circumstances) located on its leading edge. In fact, in Langacker's (2009) Reality Model, the "reality-within-actuality" covers what he calls basic reality ("what the conceptualizer accepts as having [...] obtained up through the present moment" Langacker 2009: 160) and immediate reality ("the latest phase in the ongoing process of experiencing”, Langacker 2009: 203). But it does not subsume the third kind, elaborated reality, which reflects "our capacity to imagine objects and occurrences and to contemplate their epistemic status" (Langacker 2009: 174-175). Although it is difficult to trap him in his words, Langacker's examples suggest that elaborated reality belongs to virtual plane. If in Jill has a pencil the virtual pencil is actualized through clause structure (has a), in Jill needs a pencil it is not and remains virtual (within Jill's "need" space) because the clause 
is not "sufficient to establish its actuality" (Langacker 2009: 120). ${ }^{11}$ This is what is called a virtual instance: a concrete object but in virtual plane.

Langacker's account unquestionably contains traces of Deleuze's and Žižek's thinking. For one thing, the virtual is not contrasted with or deprived of an aspect of reality; indeed, in Frank Brisard's (2010: 510) laconic but very apt formulation, virtuality is "a different reality than the speaker's here-and-now". Secondly, parallel to Deleuze's virtual wind-cum-ocean configuration being actualized in the form of hurricanes, Langacker's inherently virtual bare nouns (house) can be actualized through clause structure (He has a house). ${ }^{12}$

To add more detail to the picture, Langacker's virtual plane is neither amorphous nor homogeneous but subsumes several sub-planes:

- $\quad$ type plane: e. g. bare nouns (actress), which may be actualized in usage (John met an actress) but not necessarily (in John wants to meet an actress, an actress remains virtual);

- $\quad$ structural plane: A cat plays with a mouse it has caught (Langacker 1999: 61; singular generics, how the world generally "works");

- generalization plane: Three times during a class students asked intelligent questions (Langacker 2005: 67; probably a different student acted each time - the situations are then generalized);

- $\quad$ hypothetical plane: If drinking beer enhances endurance, Zelda can run a marathon (Langacker 2005: 68; both the subordinate and the matrix clauses are located within virtual plane as merely a hypothetical state and event, respectively).

Can this model be found compatible with Peirce's view of the symbol? It indeed can. First, Langacker's conventional linguistic unit and Peirce's symbol can be calibrated under the rubrics of psychological habit (automatized processing or entrenchment) and social agreement (contract, law, or rule) (Kowalewski 2016). (Recall in this context Bartmiński's languageentrenched, intersubjective (social) community of thoughts.) Second, Langacker's world can be the real world, a default setting, or "a derivative one, like the imagined world of a myth or a novel" (Langacker 1999: 42). Similarly, for Peirce (1909/1998: 493), "[t]he Object of the sentence 'Hamlet was insane' is the Universe of Shakespeare's Creation so far as it is determined by Hamlet being a part of it". Furthermore, symbolization, as it is conceived of by the two scholars, involves generalization. Peirce (1903/1998: 275) proposes that "a genuine symbol is a symbol that has a general meaning", an idea he took from John of Salisbury's (1909/1998: 498) 12 $2^{\text {th }}$-c. Metalogicus: Nominantur singularia, sed universalia significantur, i. e. "[Signs] name singulars/individual things, while they signify universals". This reminds one of Langacker's three types of virtual plane: type plane, structural plane, and generalization plane, which all arise through generalizations, albeit of a different sort (cf. above). ${ }^{13}$

\footnotetext{
${ }^{11}$ Langacker acknowledges his indebtedness to Verhagen (1986: 123-124) for this idea.

12 Admittedly, what does distinguish Deleuze from Langacker, is that for the former the virtual is real by definition.

13 This leaves out hypothetical plane, whose virtuality derives from a construction of a qualitatively different mental space.
} 
We are in a position now to link metonymy and virtuality, in both Peirce's and Langacker's sense. Indeed, Langacker does precisely that, with regard to his own notion of virtuality, in terms of the indeterminacy of grammatical coding. For grammatical coding to be determinate, he says, there must be a precise connection between specific elements in linguistic structures and the meanings they activate. Instead,

[i]t is more common for there to be some vagueness or indeterminacy in regard to either the elements participating in grammatical relationships or the specific nature of their connection. Otherwise stated, grammar is basically metonymic, in that the information explicitly coded does not itself establish the precise connections apprehended by the speaker and hearer in using an expression. Explicit indications evoke conceptions which merely provide mental access to elements with the potential to be connected in specific ways - the details have to be established from other considerations.

(Langacker 2009: 41)

Consider Langacker's (2009: 54-57) discussion of three barrels of oil. Examples (1a)-(1c) illustrate an individual, a collective, and an indeterminate construal, respectively:
a. Three barrels of oil were sitting in the basement. (individual construal) $)^{14}$
b. Three barrels of oil were stacked in the basement. (collective construal)
c. They loaded three barrels of oil onto the truck. (indeterminate construal)

The "other considerations" here are elements of the respective clauses, notably the verbs sit, stack and load. The difference between an individual and a collective construal, however, may have more far-reaching consequences. Together with the individual-to-collective focus shift, there may also occur an accompanying shift from the actual barrels to the volume of the oil contained in them. The two can be combined in a single usage, as in (2):

\section{To heat our house last winter we burned the three barrels of oil which had} been sitting in the basement for several years.

An interpretation that derives from the sentence's grammatical coding is [three barrels [of oil]] but a more likely one is [[three barrels of] oil], metonymically related to the first. Focus on oil is clearer in (3), due to the use of the pronoun $i t$ :

$$
\text { We piped in three barrels of oil and burned it over the winter. }
$$

The actual containers are not involved in the process of burning: the content inside is. The containers only act as virtual entities "in terms of their potential for holding a given quantity" (Langacker 2009: 55). But since, as we have seen, virtuality must not be confused with potentiality, we can add precision to Langacker's interpretation: the containers' potential has the capacity to actualize and does actualize (tautologically: "does actually actualize") in the form of the substance being burned. Therefore, virtual entities do not involve a potential "without actual efficiency" (Peirce 1902: 763) but the kind that exists "in a universe that empowers potential Xs to become actual Xs" (Esposito 2002: 1). ${ }^{15}$ This is indeterminacy of grammatical coding in action, in that there is no one-to-one relationship between form and

\footnotetext{
${ }^{14}$ If this example does not seem individual enough, consider e. g. He bought three barrels of oil over three successive Mondays: one per week.

15 Recall here Peirce's example of animal instinct: instinctive behavior has the efficiency of and is actualized as if it were rational (in the sense of reason-based) behaviour.
} 
content: the form three barrels does not code the amount of oil $(X)$ in a determinate manner but has the efficiency of $X$. Barrels are not oil but their mention provides mental access to it.

This brings us back to the trapezium and the idea of a form activating the whole configuration: the form is a virtual trapezium (a virtual $X$ ), not just in the sense of having a potential to activate $X$, but actually doing so through its efficiency to act as $X$. The trapezium (or any other conceivable configuration of linguistic form, the associated conceptual structure, the projected world, all in the context of culture) functions as a whole that becomes actualized through the triggering mechanism of language use. Reality in the bottom right apex also enters the picture, although as an indirectly approximated background, available through a cognitive-cultural filter.

\section{The integral sign conception}

To again give history its due, these ideas are far from novel. Consider Dwight Bolinger's forceful argumentation, which suggests that the form-meaning relationship is much more intimate than is usually acknowledged:

We are accustomed to regarding the reaction of mouthwatering at sight (visual image) of a lemon as "natural", and the same reaction on hearing (auditory image) the word lemon as "arbitrary". But once the activity of the word has been integrated into the individual's system the reactions based upon it are as "natural" as any other. The sound lemon becomes a part of the sensory complex 'lemon' just as the sound of a bell, heard frequently (but not always) when other bell-stimuli are presented, becomes part of the sensory complex 'bell'. The "form" lemon is now a part of the "meaning" 'lemon', and may be abstracted from it to represent it, on the basis of the part standing for the whole, just as a pictorial image or a smell or a taste may be abstracted from the whole and used to represent it.

(Bolinger 1949: 54)

This predates contemporary encyclopedic views on linguistic semantics (discussed at length in e. g. Haiman 1980, Langacker 1987, or Peeters 2000), according to which a word's form is but an aspect of a related body of knowledge, triggered by that word and entertained by the speaker. More importantly, however, Bolinger proposes to reverse the very conception of the linguistic sign. Rather than being an association of primarily distinct entities (form and meaning, the signifier and the signified, the phonological and semantic poles, etc.), it is viewed as a holistic entity, where the two (or more) aspects are inherently integrated and the form can only be abstracted from it with some effort. Says Bolinger (1949: 54): "The parts usually abstracted are those most convenient to handle and carry about - in particular, language and graphic representation".

Surprisingly, similar thinking can be found in the work of Saussure (2006: 4), expressed through an analogy that Bolinger could not have possibly known (Saussure's notes that contain it were only discovered in 1996), namely that of air as a chemical mixture of nitrogen and oxygen. It is possible to remove one of the gasses from the mixture ("nothing joins the mass of nitrogen [...] to the mass of oxygen") but air would then cease to be what it is. Crucially, we interact with air qua air, a substance with unique qualities irreducible to those of its components, a well-known phenomenon of emergent properties. ${ }^{16}$ Even if we do know

\footnotetext{
16 This is a better analogy than the famous "sheet of paper", whereby "one can neither divide sound from thought nor thought from sound; the division could be accomplished only abstractedly, and the result would be
}

ISSN 1615-3014 
that nitrogen and oxygen are more basic than and primary to air, this is the perspective of natural sciences, whereas the anthropocentric everyday perspective, fundamental to language, is precisely the reverse: people breathe and have been breathing air long before they knew anything of its composition, and indeed irrespective of that knowledge.

Thus, when Langacker (1987: 156) claims that the reasons for postulating "an autonomous, dictionary-type conception of linguistic semantics" have been "aprioristic", we can see how the encyclopedic view and the sign-as-an-integral-unit view dovetail. Moreover, the idea of form acting as a virtual (entire) configuration it metonymically activates should now be easier to accept: in fact, one would have to wonder how it could not do so, being inherent in the configuration as the latter's integral aspect.

\section{Recapitulation: metonymy through virtuality qua efficiency}

The length of the discussion above calls for a synthetic and concise recapitulation. On the one hand, to claim that there is not a qualitative difference between dyadic models of the sign, as the ones proposed by Saussure, Langacker, or Bühler, the triadic models of Gomperz or Ogden and Richards, and the ones proposed by Heger or in the present work, would be little short of gratuitous. On the other hand, however, the mechanism thanks to which the sign "means" (or better: stimulates conceptualizers to construct meanings in their minds), i. e. thanks to which a form relates to what is postulated within the configuration beside it concepts, cultural symbolic meanings, experiential projections of entities in reality - is fundamentally the same. The form activates the whole configuration, with some of its portions being more salient than others, in a fashion that is metonymic (the form and the rest of the configuration are contiguous) because it is virtual (the form has the efficiency of the configuration).

Crucially, the semiotic trapezium is never rid of reality, nor is its existence denied. Rather, the point is that reality remains beyond our direct grasp and symbolic culture emerges as a result of our quest to understand and interpret reality to the extent that we can. This does not render the process of symbolization any less "real", but it does render it "real through the virtual", "subjectively real", i. e. real for language speakers and participants in cultures. It is therefore tempting to speak not about an activation of "nearly the whole trapezium" (cf. above), but of "virtually the whole trapezium": even if not the entire trapezium is actually activated, it effectively is. In other words, the "incomplete" trapezium with the bottom right apex downplayed is virtual in the sense of having the efficiency of the whole. The inaccessibility of the real world is thus not problematic, for we do sufficiently well with language, concepts, culture, and the projected world.

In language, the only objectively accessible entities are linguistic forms (Langacker's phonological pole), but if the sign is viewed as an integral and holistic unit, then the abstraction and isolation of form is a process that requires "non-default settings". The default is a dynamic activation of the (virtually) entire semiotic trapezium. The activation proceeds

either pure psychology or pure phonology" (Saussure 1913/1966: 133). While Saussure's intention is clear - to emphasize the intimacy of the form-content connection - the analogy is imperfect in that it is possible to think of a sheet of paper as a surface for writing on, rather than an object for cutting. When used for this purpose, one side certainly suffices and the other, however real, becomes negligible.

ISSN 1615-3014 
through metonymy, which, in turn, operates through virtuality-qua-efficiency. It is along these lines that I propose to seek answers to the question of what language is and how it means.

\section{Reference}

Baldinger, Kurt (1967): "Structures et systemes linguistiques ». Travaux de Linguistique et de Littérature 5/1: 123-139.

Bartmiński, Jerzy (2001): "Język w kontekście kultury". [Language in the context of culture] In: Bartmiński, Jerzy (ed.): Współczesny język polski, $2^{\text {nd }}$ edition. Lublin, Wydawnictwo UMCS: $13-22$.

Bartmiński, Jerzy (2012): Aspects of Cognitive Ethnolinguistics. Sheffield/Oakville, CT: Equinox.

Benveniste, Émile (1939): « Nature du signe linguistique ». Acta Linguistica 1: 23-29. doi: 10.1080/03740463.1939.10410844.

Bolinger, Dwight Le Merton (1949): “The Sign is Not Arbitrary". Boletín del Instituto Caro y Cuervo (= Thesaurus) 5: 52-62.

Brisard, Frank (2010): "Aspects of Virtuality in the Meaning of the French Imparfait". Linguistics 48/2: 487-524. doi: 10.1515/LING.2010.015.

Bühler, Karl (1934/2011): Theory of Language. The Representational Function of Language. Amsterdam/Philadelphia: Benjamins.

Crocker, Stephen (2001): "Into the Interval: On Deleuze's Reversal of Time and Movement". Continental Philosophy Review 34: 45-67.

Cuyckens, Hubert/Berg, Thomas/Dirven, René/Panther, Klaus-Uwe (eds.) (2003): Motivation in Language. Amsterdam/Philadelphia: Benjamins.

Deleuze, Gilles (1966/1988): Bergsonism. New York: Zone Books.

Deleuze, Gilles (1968/1994): Difference and Repetition. New York: Columbia University Press.

Echard, William (2006): "Sensible Virtual Selves: Bodies, Instruments and the Becomingconcrete of Music". Contemporary Music Review 25/1-2: 7-16.

Esposito, Joseph (2002): "Virtuality”. In: Queiroz, João/Gudwin, Ricardo (eds.): Digital encyclopedia of Charles Peirce. www.digitalpeirce.fee.unicamp.br/virtuality.rtf [15.01.2014].

Frege, Gottlob (1892): „Über Sinn und Bedeutung“. Zeitschrift für Philosophie und philosophische Kritik, NF 100: 25-50.

Głaz, Adam/Danaher, David /Łozowski, Przemysław (eds.) (2013): The Linguistic Worldview: Ethnolinguistics, Cognition and Culture. London: Versita.

Gomperz, Heinrich (1908): Weltanshauungslehre, zweiter Band: Noologie. Jena: Eugen Diederichs.

Heger, Klaus (1969): «L'analyse sémantique du signe linguistique ». Langue française 4: 44-66.

Haiman, John (1980): “Dictionaries and Encyclopedias”. Lingua 50/4: 329-357.

Hinton, Leanne/Nichols, Johanna/Ohala, John (eds.) (1994): Sound Symbolism. Cambridge: Cambridge University Press.

Jackendoff, Ray (1983): Semantics and Cognition. Cambridge, MA: MIT Press. 
Jakobson, Roman (1962): „Zeichen und System der Sprache: Diskussionsbeitrag“. Schriften zur Phonetic, Sprachwissenschaft und Kommunikationsforschung 4: 50-56. [English translation: (1980): "Sign and System in Language: A Reassessment of Saussure's Doctrine". Poetics Today 2/1a: 33-38.]

Kardela, Henryk (1990): “Ogdena i Richardsa trójkąt uzupełniony, czyli co bada gramatyka kognitywna" [Ogden and Richards' triangle closure: What does cognitive grammar investigate?]. In: Bartmiński, Jerzy (ed.): Językowy obraz świata. Lublin, Wydawnictwo UMCS: $15-40$.

Kowalewski, Hubert (2016): Motivating the Symbolic. Towards a Cognitive Theory of the Linguistic Sign. Frankfurt a. M.: Lang.

Krąpiec, Mieczysław Albert (1995): Język i świat realny. [Language and the Real World] Lublin: Redakcja Wydawnictw KUL.

Lakoff, George (1987): Women, Fire, and Dangerous Things. What Categories Reveal about the Mind. Chicago: University of Chicago Press.

Lakoff, George/Johnson, Mark (1999): Philosophy in the Flesh. New York: Basic Books.

Langacker, Ronald Wayne (1987): Foundations of Cognitive Grammar. Vol. 1. Theoretical Prerequisites. Stanford: Stanford University Press.

Langacker, Ronald Wayne (1999): "Virtual Reality". In: Hwang, Shin Ja/Lommel, Arle (eds.): LACUS Forum XXV. Fullerton, CA: LACUS: 41-69. [Reprinted in Studies in the Linguistic Sciences 29/2: 77-103, 1999.]

Langacker, Ronald Wayne (2005): “Two Problems Virtually Resolved”. In: Stanulewicz, Danuta/Kalisz, Roman/ Kürschner, Wilfried/Klaus, Cäcilia (eds.): De lingua et litteris. Studia in honorem Casimiri Andreae Sroka. Gdańsk, Wydawnictwo Uniwersytetu Gdańskiego: $65-70$.

Langacker, Ronald W. (2009): Investigations in Cognitive Grammar. Berlin/New York: de Gruyter.

Lyons, John (1981): Language and Linguistics. An Introduction. Cambridge: Cambridge University Press.

Malinowski, Bronislaw (1923/1952): “The Problem of Meaning in Primitive Languages". Supplement I to Ogden, Charles Kay/Richards, Ivor Armstrong (1952 [1923]): The Meaning of Meaning. New York/London: Routledge/Harcourt: 296-336.

Massumi, Brian (2002): Parables for the Virtual: Movement, Affect, Sensation. Durham, NC: Duke University Press.

Ogden, Charles Kay/Richards, Ivor Armstrong (1923/1952): The Meaning of Meaning. A Study of the Influence of Language upon Thought and of the Science of Symbolism. New York/London: Routledge/Harcourt.

Panther, Klaus-Uwe/Radden, Günter (eds.) (2004): Motivation in Grammar and the Lexicon. Amsterdam/Philadelphia: Benjamins.

Peeters, Bert (ed.) (2000): The Lexicon-Encyclopedia Interface. Amsterdam: Elsevier.

Peirce, Charles Sanders (1902): "Virtual". In: Baldwin, James Mark (ed.): Dictionary of Philosophy and Psychology, Vol. 2. New York, Macmillan: 763.

Peirce, Charles. Sanders (1894/1998): "What is a Sign?” In: The Peirce Edition Project (ed.): The Essential Peirce. Selected Philosophical Writings, Vol. 2 (1893-1913). Bloomington, Indiana University Press: 4-10. 
Peirce, Charles Sanders (1899/1998): "The First Rule of Logic". In: The Peirce Edition Project (ed.): The Essential Peirce. Selected Philosophical Writings, Vol. 2 (1893-1913). Bloomington, Indiana University Press: 42-56.

Peirce, Charles Sanders (1903/1998): "Sundry Logical Conceptions". In: The Peirce Edition Project (ed.): The Essential Peirce. Selected Philosophical Writings, Vol. 2 (1893-1913). Bloomington, Indiana University Press: 267-288.

Peirce, Charles Sanders (1909/1998): "Excerpts from Letters to William James". In: The Peirce Edition Project (ed.): The Essential Peirce. Selected Philosophical Writings, Vol. 2 (1893-1913). Bloomington, Indiana University Press: 492-502.

Radden, Günter/Panther, Klaus-Uwe (eds.) (2004): Studies in Linguistic Motivation. Berlin/New York: de Gruyter.

Radden, Günter/Kövecses, Zoltán (1999): “Towards a Theory of Metonymy”. In: Panther, Klaus-Uwe/Radden, Günter (eds.): Metonymy in Language and Thought. Amsterdam/Philadelphia, Benjamins: 17-59.

Saussure, Ferdinand de (1916/1966): Course in General Linguistics. Translated from the French by Baskin, Wade. New York/Toronto/London: McGraw.

Saussure, Ferdinand de (2006): Writings in General Linguistics. Transl. Carol Sanders/Matthew Pires. Oxford: Oxford University Press.

Scotus, John Duns (1307/1975): God and Creatures: The Quodlibetel Questions. Transl. Felix Alluntis/Allan Wolter. Princeton: Princeton University Press.

Smith, Bradley (2009): "On Reality and Virtuality: A Study of Time-spaces in Plowing the Dark". Mosaic 42/3: 95-108.

Ullmann, Stephen (1962): Semantics. An Introduction to the Science of Meaning. Oxford: Blackwell.

Verhagen, Arie (1986): Linguistic Theory and the Function of Word Order in Dutch: A Study of Interpretive Aspects of the Order of Adverbials and Noun Phrases. Dordrecht: Foris.

Warren, Beatrice (1999): "Aspects of Referential Metonymy". In: Panther, KlausUwe/Radden, Günter (eds.): Metonymy in Language and Thought. Amsterdam/Philadelphia, Benjamins: 121-135.

Whitney, William Dwight (1875): Language and Language Study: Twelve Lectures on the Principles of Linguistic Science. New York: Dover Publication.

Wright, Ben (2004): The Reality of the Virtual. Film. Olive film opus. 